\title{
Structural Design and Analysis of Trailer System for Photo Voltaic Cells
}

\author{
B.Sandhya Rani ${ }^{*}{ }^{1}$, P.H.V.Sesha Talpa Sai ${ }^{2}$, Y. Vijay Kumar $^{1}$, C.Udayakiran ${ }^{1}$ \\ ${ }^{I}$ Department of Mechanical Engineering, J.B.Institute of Engineering and Technology, Hyderabad, India- \\ 500072. \\ ${ }^{2}$ Department of Mechanical Engineering, Centre for Innovation, Incubation \& Entrepreneurship (CIIE), \\ Malla Reddy College of Engineering \& Technology, Dhulapally, Secunderabad-500 100.
}

\begin{abstract}
Non conventional power devices viz. Photo voltaic cells are not seeing much of light due to a practical draw back that sun should be normal to the plane of the device all the times. But presently non conventional power devices are being installed in a fixed position and in a day, position of sun keeps changes from morning till evening with relative to the non conventional power device. Because of this practical difficulty most of the time very minimal power that emits from the sun will be utilized for generating electricity. To overcome this limitation a trailer system is needed which enables the non conventional power device to change its orientation (Rotates) continuously such that it always remains normal to the sun with which effectiveness of the non conventional power devices can be increased tremendously. Existing systems are having electronic controllers which are complex to handle and also costlier. Moreover they demand more power for their own controller and also their maintenance is tedious. Hence a trailer system which dispenses utility of so called complex electronic controller through the aid of mechanical elements is evolved for non conventional power applications. To start with all the subsystems of the proposed configuration are identified and sizing is evolved through design calculations. Further design adequacy has been assessed through Finite Element Analysis.
\end{abstract}

Keywords: Nonconventional power device, Photo voltaic cell, Orientation, Configuration, Finite element analysis.

\section{Introduction}

Generation of electrical power from non conventional sources of energy is the state of art as they are abundantly available. Though this concept has come way back they are not seeing much of light due to certain drawbacks. One of such drawbacks is the non conventional power device (For ex: non conventional photo voltaic cell) installed on roof top should always face the sun i.e. sun should be normal to the plane of the device all the times as the heat transfer occurs by radiation and the condition imposed by radiation heat transfer is heat source should be normal to the absorber in order to achieve effective heat transfer. But presently non conventional power devices are being installed in a fixed position and in a day, position of sun keeps changes from morning till evening with relative to the non conventional power device. Because of this practical difficulty most of the time very minimal power that emits from the sun will be utilized by the non conventional power device for generating electricity. To overcome this limitation a trailer system is needed which enables the non conventional power device to change its orientation continuously so as to enhance its effectiveness. One such system is shown in Figure 1.

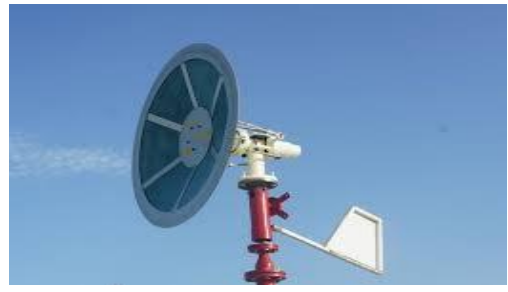

Figure 1. Trailer system

As it can be seen trailer system shown above is equipped with electronic servo control system and hence tedious to handle and maintain. Hence it is decided to explore the possibility of simplifying the design of trailer system.

Design and construction of a prototype for trailer system for non conventional power applications with two degrees of freedom, which detects the sunlight using photocells is presented [1]. Design and execution of a trailer system dedicated to the PV conversion panels is discussed. The proposed single axis trailer system device ensures the optimization of the conversion of non conventional energy into electricity by properly orienting the 
PV panel in accordance with the real position of the sun [2]. Design of a low cost, $0.9 \mathrm{~kW}$ non conventional tracking photo-voltaic (PV) array system took up as part of an undergraduate senior project. The trailer system for non conventional power applications is interfaced with a $1 \mathrm{~kW}$ wind turbine, a deep cycle battery storage system, a charge controller and an inverter. Non conventional tracking is realized through complex digital circuit [3]. LDR light detector is used to trace the coordinate of the Sun. While to rotate the appropriate position of the panel, a DC geared motor is used. The system is controlled by two relays as a driver and a microcontroller as a main processor. This project is covered for a single axis and is designed for residential usage [4]. The tracker uses two Nema 23 bipolar stepper motors to rotate 2 photovoltaic cells around the altitude and azimuth axes. Three tracking algorithms are implemented to track the sun. The first moves the PV panel in little squares in spherical coordinates, finds the point on the square with the best voltage, and moves there, then starts over. The second moves in a little square, finds the voltage gradient, and uses that to decide where to move. The third uses the second strategy to find 5 or 6 good points spread 1hour apart [5]. An innovative system for tracking the sun which is based on the use of a commercial web cam as the sensor element is proposed. An experimental electro-mechanism was designed and developed to evaluate its accuracy and efficacy in tracking the sun under different weather conditions [6]. As can be seen, all the research focus on design of most complicated systems like servo systems. Further it is also noticed that all the systems are having electronic controllers and hence costlier. Moreover they demand more power for their own controller and also their maintenance is tedious.

Based on the limitations brought out as an outcome of literature review it is observed that a great need exists for development of trailer system built with all mechanical systems for non conventional power applications.

\section{Design Philosophy}

As mentioned in earlier section, primary idea is to replace complex electronics in existing trailer systems (Except motor) with simple mechanical elements so as to feel the comfort with regard to handling, maintenance, etc. Motor has been chosen as means of actuating non conventional power device between sun rise and sun set. Taking total time between sun rise and sun set, speed of motor needed to rotate non conventional power device is estimated to be $0.001 \mathrm{rpm}$. Gear motor has been considered for the proposed design as it is the lowest speed motor available (1 rpm). Corresponding speed reduction is 1:1000 (i.e. from $1 \mathrm{rpm}$ to $0.001 \mathrm{rpm}$ ), which is planned to be met by incorporating worm and worm gear through two stage reduction. Proposed design with all subsystems is shown in Figure 2.

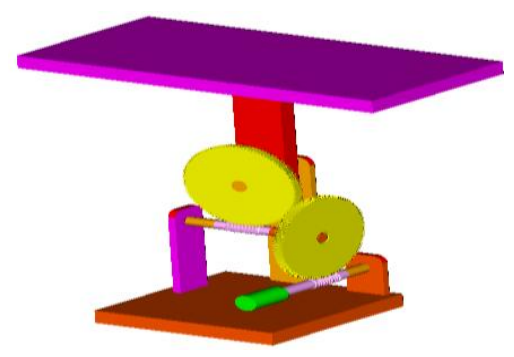

Figure 2. Proposed design

From the above figure the following components are identified for which detailed design is carried out.

- Worm (Stage $1 \& 2)$

- Motor

- Worm gear (Stage $1 \& 2)$

- Shaft

- Bearing

\section{Design Configuration}

Following design inputs are considered.

- $\quad$ Pressure angle $=20^{\circ}$

- $\quad$ Torque factor $=1.2$

- Number of stages $=2$ (Speed reduction)

Outcome of design is summarized in Table 1. 
Table 1: Design parameters

\begin{tabular}{|c|c|c|}
\hline Sl. No. & Design Parameter & Value \\
\hline \multicolumn{3}{|c|}{ Worm } \\
\hline 1. & PCD & $44.1 \mathrm{~mm}$ \\
\hline 2. & Axial pitch & $9.89 \mathrm{~mm}$ \\
\hline \multicolumn{3}{|c|}{ Worm gear } \\
\hline 1. & PCD & $315 \mathrm{~mm}$ \\
\hline 2. & Number of teeth & 100 \\
\hline 3. & Face width & $25 \mathrm{~mm}$ \\
\hline \multicolumn{3}{|c|}{ Motor } \\
\hline 1. & Torque & $4.4 \mathrm{~N}-\mathrm{m}$ \\
\hline 2. & Rpm & 1 \\
\hline \multicolumn{3}{|l|}{ Shaft } \\
\hline 1. & Diameter & $25 \mathrm{~mm}$ \\
\hline 2. & Length & $200 \mathrm{~mm}$ \\
\hline \multicolumn{3}{|c|}{ Bearing } \\
\hline 1. & Outer diameter & $37 \mathrm{~mm}$ \\
\hline 2. & Width & $7 \mathrm{~mm}$ \\
\hline 3. & Designation & 61805 \\
\hline
\end{tabular}

First Natural Frequency $=3.2 \mathrm{~Hz}$

\section{Structural Analysis}

Structural analysis of trailer system is carried out using Finite Element Method (FEM) in ANSYS software in order to assess the design adequacy against the functional load i.e. due to rotation of the system. Maximum Von Misses stress thus obtained is compared with allowable stress and obtained the available factor of safety.

\section{Criteria}

\section{Static Analysis}

- Minimum available factor of safety should be more than the desired factor of safety (1.5).

\section{Modal Analysis}

- First natural frequency should be above the frequency associated with operating condition of mechanism i.e. $0.016 \mathrm{~Hz}(1 \mathrm{rpm})$.

To begin with geometric model of the intended design is built in 3D CAD software from its dimensions. However load bearing members are only considered for analysis. Then geometric model is converted into FE model by discretizing worm gear with shell (SHELL63) elements, shaft with beam (BEAM4) elements and non conventional power device with mass (MASS21) elements. As the trailer system is made of steel its material properties are considered for the analysis FE model at bearing end is fixed for all DOF except rotation about bearing axis.

FE model with boundary conditions is shown in

Static analysis was carried out and the corresponding Von Misses stress plot is shown in Figure 4

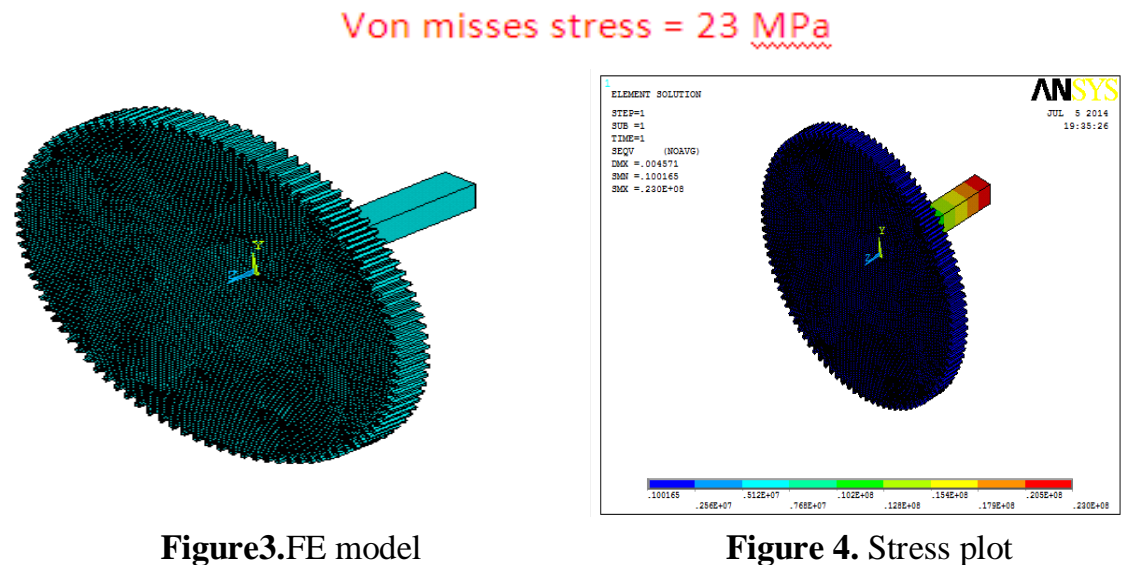

Then dynamic (Modal) analysis was also carried out. Modal analysis is the study of the dynamic properties of structures under vibration excitation. In structural engineering, modal analysis uses a structure's 
overall mass and stiffness to find the various periods that it will naturally resonate at. A modal analysis calculates the undamped natural modes of a system. These modes are given in decreasing order of period and are numbered starting from 1. Mode shape plot corresponding to first natural frequency is shown in Figure 5.

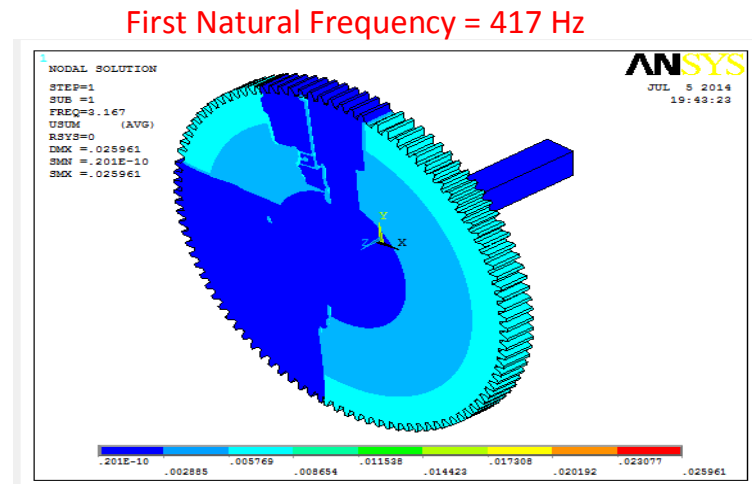

Figure 5. Mode shape plots

Outcome of analyses is summarized in Table 2.

\section{Results And Discussion}

Table 2: Analyses results

\begin{tabular}{|c|c|c|c|c|}
\hline $\begin{array}{l}\text { Sl. } \\
\text { No. }\end{array}$ & Result & $\begin{array}{c}\text { Maximum } \\
\text { Value }\end{array}$ & $\begin{array}{c}\begin{array}{c}\text { Allowable } \\
\text { value }\end{array} \\
\end{array}$ & $\begin{array}{c}\text { Factor of } \\
\text { safety }\end{array}$ \\
\hline \multicolumn{5}{|c|}{ Static } \\
\hline 1. & Von Misses stress & $23 \mathrm{MPa}$ & $330 \mathrm{MPa}$ & $>5$ \\
\hline \multicolumn{5}{|c|}{ Modal } \\
\hline 2. & $\begin{array}{ll}\text { First } & \text { natural } \\
\text { frequency } & \end{array}$ & $3.2 \mathrm{~Hz}$ & $>0.016 \mathrm{~Hz}$ & -- \\
\hline
\end{tabular}

- Maximum Von Misses stress is observed to be $23 \mathrm{MPa}$.

- Available factor of safety is observed to be $>5$ which is more than minimum desired factor of safety (1.5). Hence the design is safe.

- Frequency of the intended system corresponding to first bending mode is found to be $3.2 \mathrm{~Hz}$ which is much above the frequency associated with operating condition of mechanism i.e. $0.016 \mathrm{~Hz}$.

- Hence system doesn't experience resonance..

\section{Conclusion}

Trailer system for non conventional power applications is evolved which changes its orientation so that it will have always line of sight with respect to sun. Intended system incorporates mechanical means without employing conventional electronic means. Design adequacy of the configuration is assessed with the aid of FE analysis which conveyed a message that the design is safe.

\section{Acknowledgment}

The authors sincerely acknowledge the valuable support extended by Dr. Devarayapalli Kamakshaiah Charyulu, Professor \& Head of the Science and Humanities Department, Bhaskar Engineering College, Hyderabad, India. The authors thank Dr. Niraj Upadhaya, Principal, J B Institute of Engineering and Technology, Hyderabad, India for the support.

\section{References}

[1]. Nader Barsoum, and Pandian Vasant, "Simplified Non conventional Tracking Prototype", Journal on Technology \& Optimization, 2010:Vol 1, pp.38-45

[2]. Tiberiu Tudorache, and Liviu Kreindler, "Design of a Non conventional Tracker System for PV power Plants", 2010: Vol. 7, No. 1: pp. 23-39.

[3]. S. Lakeou, E. Ososanya, B.O. Latigo, and W. Mahmoud, "Design of a Low-cost Non conventional Tracking Photo-Voltaic (PV) Module and Wind Turbine combination System", Technical paper.

[4]. Asmarashid Ponniran, Ammar Hashim, and Handy Ali Munir, "A Design of Single Axis Sun Tracking System", The 5th International Power Engineering and Optimization Conference (PEOCO2011), Shah Alam, Selangor, Malaysia. 2011: p.107-110.

[5]. Toby Peterson, Justin Rice, and Jeff Valane, "Non conventional Tracker", Spring, 2005:.

[6]. Minor M. Arturo, and García P. Alejandro, "High precision non conventional tracking system", World Congress On Engineering, London, U.K. 2010 . 